\title{
Huanggang Middle School Basketball Teaching Present Situation and Countermeasure Research
}

\author{
Weiqi Jiang ${ }^{1, *}$, Kunling Qin ${ }^{2}$, Bo Huang ${ }^{1}$, Feng LI $^{1}$ \\ ${ }^{1}$ Institute of Physical Education, Huanggang Normal University, Huangzhou 438000, Hubei, China \\ ${ }^{2}$ Yidu Gaobazhou Middle School, Yidu 443300, Hubei, China \\ tiyuxi@qq.com
}

\begin{abstract}
As a western spirit of competition and the combination of Chinese traditional Confucian heritage culture imports, as a popular sport basketball movement has been deeply in our whole society culture, and I get a feedback in various industries, particularly in the field of education. As a matter of both fitness and entertainment sports, its status in school education is self-evident. Our country is a vast country, each region culture shows large comprehensive regional unity, under the circumstance of basketball in the cultural perspective, popularization and development of mapping of splendor. Economically developed areas and poverty-stricken areas in the economic factors caused cultural development has significant differences on the comparative, education mature areas and the less developed areas in the quality of teachers, students, infrastructure hardware standard, and scheduling, coach system complexity and so on also affects the conduct and control of the specific sports. Together in a big data chaos system, how to analyze the regional relatively small data is mapped to a specific business is how to make regional comprehensive evaluation of basketball sport, and with high precision, high robustness, high generalization ability, is a major issue in front of scientific research personnel. In this paper, by introducing fuzzy comprehensive evaluation system, will have a reasonable quantitative mixed data and avoid the disadvantages of the qualitative discussion, namely people subjective factors on the objective law of noise mapping, by avoiding noise can establish reasonable expert evaluation index system. After introducing modern intelligent algorithm of this paper and the huanggang district regional data integration analysis, algorithm between the groups of mutual competition, won both open and critical criteria. By putting a macro perspective of small-scale comprehensive system construction, obtained the wildcard judging criteria of physical education. Application of the wildcard standard, analysis for huanggang district basketball education has a more conservative evaluation score, through the comprehensive analysis of the seven factors, pointed out that the region of expert system of basketball culture has a certain background, teachers have a certain strength, teaching achievement is significant. And in the competing situation and lacking discipline system construction aspect, needs to be systematic improvement and competition system, teaching the introduction of new forms, etc. The above analysis is not only suitable for huanggang region, scholars can algorithm and implementation of network group of abstract, generalization algorithm model in any actual physical education evaluation strategy, and make a guidance and forward-looking policy blueprint.
\end{abstract}

Keywords: physical education; Teaching methods; High school basketball

\section{INTRODUCTION}

As an impact and confrontational human recreational activities, basketball around the world with a wide range of entertainment functions and penetration, the human body through the implementation of the mechanical physical activities and flexibility in parallel, can obtain larger cardiopulmonary function to expand the utility and bones healthy development opportunity, at the same time through the nerve stimulation and response sensitivity training can improve human brain development and active thinking ability. With the introduction of this activity, and implement to the secondary school education, can improve the adolescent comprehensive quality in our country. As an import, the sport was invented by an American, its implementation rules and advocates the spirit of the western characteristics, such as equality, competition, such as freedom of thought. Its essence is under the terms of the regularity, through the established human activities, and through collaboration with a high level of activity of biological characteristic. This activity in the national penetration rate is very 


\section{Weiqi Jiang et al.}

high, and through the integration of traditional culture and reborn the sport, both have the characteristics of western classical and new ecological movement, and both rendering of Chinese traditional culture and special characteristics of since the new culture movement [1-3].

From the last century in China began to open the door of the economy, foreign culture and economic mode to bring the huge impact of traditional culture and economic model. Since the successful hosting of Beijing Olympic Games in 2008, the Chinese spirit culture of the people brought huge baptism, sports, and therefore plays an important role, to the national education also made an own contribution [2-6]. Basketball is popular with the masses, especially for students in a high school education, enriched their amateur life, basketball is also the performance of combining exertion and rest, to study also to have certain help.

Is the current domestic basketball development environment and conditions, our country is in a disadvantage, want to enter the world still needs a period of time. Mainly reflected in the competitive level is poor, need to put more and more urgent in competitive level. Basketball is just a representative of the competitive projects, comprehensive strength of ascension, along with our country sports developed also has sprung up, has had the impact on the world first-class basic conditions.

Taking huanggang region of middle school students as the research object, USES the literature material law, questionnaire survey research methods, mathematical statistics, logic analysis, consult a large number of related courses and physical education science, combined with BP neural network, support vector machine (SVM), SOM algorithm, discrete neural networks, the analytic hierarchy process, fuzzy clustering method algorithm is introduced, such as statistics and related basketball status, training arrangement, training methods and research analysis of the current situation of the school basketball, put forward the corresponding countermeasures to promote the huanggang area middle school basketball sports provide theoretical basis for sustainable development in education [39].

In the secondary school education, sports as a compulsory subject to bound as well as the study subject, thering is no lack of some students just in order to achieve education during the period of standards were being forced to take part in physical exercise, this idea is very limited. Everyone actually in the process of exercise not only exercises the body, enhance their own quality, and cultivate bear hardships and stand hard work, the quality of perseverance. It is the most valuable for a student, this is for future enters society or further education has a unique role. These are universal, popularization of object is mainly college students, and the key is to let the students in the process of basketball to produce an understanding of their own.

Many scholars in various aspects of the construction of campus culture put forward its own views, but also recognized that campus culture is a special kind of culture, is an important part of advanced culture. In bao-an wang "in the construction of school culture in the new period" in the campus culture is a system engineering, multi-level aspects put forward the construction of campus culture should follow some principles, and attention should be paid to the problem.

Basketball culture has caused great sensation in the school now and was deeply loved by students, it is also the heavy burden of their studies, a method of relaxation; Zhong Xiting in the culture under the perspective of modern basketball sport, this paper expounds the cultural background, the significance and function of the basketball, and let more people understand basketball culture connotation; Kinsey Britain in sports cultural connotation of the wheel, the comprehensive study of literature and logic method, fully elaborated the commercial and cultural fusion and value in undertakings of physical culture and sports; Li Xishui in the theory of CUBA matches reflect the cultural connotation and campus basketball culture construction in the college students from China which caused by the CUBA league campus basketball culture phenomenon, this paper expounds the characteristics and connotation of CUBA culture, analyzes the CUBA basketball culture on campus culture, positive promoting effect of basketball culture, and agreed that should pay attention to strengthen the construction of campus basketball culture, to the prosperity and development of campus sports culture is of great significance. YanCheng spring in the study of campus basketball culture education, and discussed the significance of campus basketball culture education function and the function. Provide reference opinions for direction of physical culture education, points out that the school in a comprehensive quality education as well as strengthen sports culture education. Shuang-wen wu in 
the competitive level of the CUBA basketball league for college students and the reserve personnel training research, elaborated the CUBA is the basketball movement development to a certain stage of the new thing currently has a profound impact in adolescents. Through investigation and analysis of university basketball league, this paper discusses the CUBA athletics level and basketball reserve personnel training problems, and using factor analysis method to sort out a number of related factors, and made some Suggestions for the reference for the healthy development of CUBA [6].

\section{The Research ObJect ANd Process}

\subsection{The Research Object And Methods}

This paper several in huanggang area middle school as the research object, for college students to carry on the investigation and analysis, fully understand the understanding of culture under the perspective of basketball.

(1) Literature: According to the needs of the research content and purpose, consult, collect and organize related about basketball sports publications of the present study different materials; Through academic periodicals network query the related research on middle school students' basketball after 1997, read the 100 articles related literature, and collect the huanggang high school basketball material in recent years, from the research in the field of comprehensive grasp the status quo, lay a foundation for the paper writing.

(2) Questionnaire: According to the needs of research, design the huanggang middle school physical education teachers (basketball coaches) questionnaire and student questionnaire (basketball training). In making the questionnaire, consult the school sports expert opinions, made the necessary modification and supplement, to form the final questionnaire. Specific sampling method is: in the huanggang administrative division 19 county areas. According to each area belongs to the nature of the school take a stratified sampling method, based on what each district school "is the number of randomly chosen three high school students (basketball training), physical education teachers (basketball coaches) as sample, districts were included in the extraction of the three schools complete high school, construct the middle school, senior high school. This largely reflects the comprehensiveness and rationality of sampling middle school.

(3) The mathematical statistics method: Using Excel2003 data processing software, the investigation and the collected data into the computer for statistical processing and comprehensive analysis.

\subsection{Cultural Perspective of Huanggang Development Status of Basketball is the Yellow Area}

The basketball movement is developing rapidly all over the world, especially in the development of Chinese basketball, especially with the rise of economy entered into a rapid stage of development. The study of Chinese basketball has also been a great deal of attention, but most of the studies on basketball were primarily in terms of experience and tactical combination. For the basketball development of cultural perspective the state is still a blank. This specific sport is basketball, though, like other competitive sports training process and the law of the common, but it has its own unique place. So study the development of basketball culture perspective area state has certain positive meaning. Currently huanggang district middle school basketball education belongs to the steady rise stage. Basketball class cultural activities emerge in endlessly, especially the huanggang region of middle school, basketball culture festival, the basketball tournament, basketball extracurricular group such as a variety of cultural activities are flourishing development. But at present the basketball culture in huanggang region is faced with some problems, such as the critical period because of the high school students at the entrance, often because of learning and was forced to reduce in basketball exercise and cultural exchange, this special that basketball education in middle school under the influence of a certain stage of development. Overall in the cultural perspective in huanggang middle school basketball development although there are some problems, but the momentum is still very good.

This paper mainly studies the cultural perspective to the quantitative evaluation of middle school basketball development in huanggang, for huanggang area middle school basketball development degree evaluation to provide scientific reference. The selection of evaluation index based on analytic hierarchy process (ahp), and only in a reasonable cultural perspective to get the most reasonable evaluation result. Therefore, it is very important to the selection of relevant indicators. 


\section{Weiqi Jiang et al.}

\section{(1) Basketball culture}

Basketball culture is developing and growing environment, through the study of basketball activities both at home and abroad show that the good basketball culture is one of the root cause of the growing, is also a region the development of basketball culture degree evaluation, is reasonable evaluation culture perspective of basketball development status of important indicators. Huanggang region is obtained by visiting survey, the activities related to the secondary school basketball culture in record Numbers. Each year the number of basketball game, for example, the number of people involved, the number of basketball culture festival held every year, the number of school basketball after school in the same grade group, these are all can be quantified, and measure of huanggang district secondary school basketball culture development degree.

\section{(2) Extracurricular interest}

Middle school students' basketball interest in after school for basketball activity participation. Because of the special phase, a high school student is interested in cultivating and entrance stressful period. So region of middle school students is very important to the development of basketball culture, and in the middle school students' extracurricular interests, basketball proportion can also reflect a certain degree of development [8].

\section{(3) The results of the competition}

Basketball against class sports, in this kind of sport team collaboration is the key to winning. Degree of parameters for middle school student's basketball game reflects the region, schools, and individuals for the importance of basketball. Through statistical huanggang area middle school students to reach the number of basketball game in the cultural perspective of an objective evaluation of middle school basketball development.

\section{(4) The quality of teaching}

Middle school students' interest in basketball enlightenment and technical training is from middle school basketball teaching is basic, so high school basketball teaching quality is the key to the development of middle school students' basketball. Textbooks in huanggang high school basketball teaching material and teaching outline of carrying case statistics can be shown from the side of measure in the teaching of classroom teaching quality. For the reasonable application of the syllabus is one of the indicators reflect the quality of teaching [9].

\section{(5) Coach qualifications}

High school basketball is mainly composed of classroom teaching, and for the classroom teaching, the coach of the teaching level is one of the biggest factors. Coach teaching quality on the one hand, reflected in terms of student achievement, on the one hand, the coach itself it is important to get quality evaluation index. Due to the intuitive and has a good coach education comparative, this article statistics section huanggang high school basketball coach education as one of the evaluation index.

\section{(6) The male to female ratio}

A sport must be received common be fond of of men and women, the development of basketball development. In the cultural perspective, men's and women's concern for the love of basketball and the closer the more can reflect. As for the popularity of basketball will be affected by a certain gender but gender difference is smaller, the more middle school students under the basketball culture for the love of basketball.

\section{(7) Physiological indexes}

For middle school students looks at one of the important indicators of basketball is the determination of physical quality, every movement has it's about the body quality requirements, the basketball, too. Physiological indexes is for middle school students cannot afford to ignore, because of the high school students are in growth period need timely and accurate understanding of the physiological indicators of body, and only in this way they can better to guide and help, to do according to their aptitude. Due to the continuous development of modern science and technology, for students of the extraction of the physiological indexes are no longer limited to traditional simple measurement, this paper USES modern infinite body network routing technology for the science of real-time testing every data of the student body of the detected data processing, so as to achieve the realization of the quantitative indicators. 


\section{Conclusions}

\subsection{Summaries}

In this paper, we study the cultural perspective in huanggang middle school basketball development, first briefly describes the present situation and problems of the development of basketball culture views, introduced the current development of basketball. Then research the huanggang region of middle school students' basketball development. For often occur in the study of evaluation class development problem such as subjective, based on the research current situation of the development of cultural perspective in huanggang middle school basketball when using classical mathematics evaluation algorithm quantitatively study on the current development situation, the actual qualitative problem is transformed into quantitative evaluation problem. Get the object of study for more scientific and reasonable development of provides scientific and objective results. In this paper, based on the actual results, an in-depth study on the current state of the huanggang area middle school students' basketball development results, are put forward to sex in huanggang area and strengthen the Suggestions on the development of basketball. Not only for huanggang area can do middle school basketball arch of the development of the valuable reference at the same time also more widely. Innovation point of this article is for the quantitative mathematical algorithm to study the assessment of the qualitative research, provides a new direction to the research of basketball development, at the same time to fill the gaps in this aspect.

This article is precisely based on this model, selection of cultural perspective, this unique area a sports activities in the development of empirical study, the evidence that the region still has great development potential and good momentum of development, through the establishment of the expert model, the mathematical evaluation model in the region to show that huanggang district basketball culture has better ability in regional associativity and cultural inheritance, but there is still space for development.

\subsection{Outlooks and the Suggestion}

The national traditional culture of China to the development of basketball in China plays an irreplaceable role, but because of basketball is also a project introduced from abroad, started in the late than abroad, history is relatively short, but this does not prevent the development of basketball in our country, especially under the breeding of Chinese traditional culture, is developing rapidly. Can bring out the best in each other and with foreign development, promote the development of basketball industry to grow. Development trend of the national sports is a country with people's values are inseparable, aesthetic temperament and interest of a nation is bound to the contents have an effect on the development of sports, the development situation and style are based on the basketball movement under the influence of Chinese traditional culture.

In adolescent students, especially the plot of the boys would have a love of basketball, and this is a unity of the Chinese nation as a whole, in ancient times is the power of unity. When playing basketball is mutual cooperation, have what experience is group share, this also is helpful for the growth of the teenagers. Chinese national culture is a complex and huge system, a number of excellent cultural traditions is formed in the long historical development process, of course, every coin has two sides, also produce certain negative factors at the same time, it accords with the objective law of things development. In the process of modern athletic basketball development in our country, due to the lack of Chinese traditional culture tradition, make the mistake of contemporary athletic basketball into Chinese culture, has affected the healthy development of modern athletic basketball in our country, hindered the implementation of Chinese contemporary competitive basketball new breakthrough. Of course basketball shouldn't be stalled because of the influence of traditional culture, the resistance is the motivation, this also is the impetus to the development of basketball sports.

\subsubsection{Strengthen cultural exchanges}

Because of the difference of Chinese and western culture, the teacher for basketball curriculum will also be different. But nature is with the national cultural characteristics, and national cultural mastery, pedigree. Because the sports development in the west development of China's relatively earlier, so we can draw lessons from the experience of many. Can grab from the teaching system and mode, the textbooks of the law, the traditional idea, ideology and so on is introduced to achieve mastery through a comprehensive, absorbs the essence and discard its dross, to minimize the deviation in the understanding. 


\subsubsection{Basketball culture system reforms}

Through the empirical analysis can dig out the competition mechanism in the evaluation of huanggang regional basketball development has a certain conservative evaluation, through this can have an important empirical findings is that should and must vigorously introducing competition mechanism, in the context of our traditional Confucian culture, geographical factors may have certain effects on its culture, but as a whole, the competitive level of group consciousness has not been aroused, shall be eliminated mechanism, or natural selection mechanism of the appropriate return. As import, when we draw the essence, should be denying to go back to the spirit of our own culture, specific measures can be gained with the evaluation of expert system, through the collection of advantages of resources for education resource integration, the introduction of advanced equipment and basketball talent, by increasing the venue, number, and the competition mechanism to stimulate the basketball education long-term development.

Empirical analysis of another focus is the reform of the system of system, we in the expert system can get the rational sports industry ecosystem need to be further improved, society can be seen, regional developing system is not perfect under the refraction of the whole society of some drawbacks of sports education system, these shortcomings by mining in regional perspective can often teach an unobstructed view of how to set up scientific system is a grand proposition, this article only gives a preliminary proposal, should set up the pyramid forms of development mode, the comprehensive level of cultural and sports level, will become energetic cultural and sports industry in China have a life to be competitive.

To sum up, in this paper, from a perspective of national culture, to huanggang district middle school sports development situation has carried on the comprehensive evaluation, based on the fuzzy comprehensive evaluation algorithm will be purely physiological indicators and the physical and chemical factors to other abstract factors of coupling, good robustness were obtained through the AHP algorithm iteration factor model of high precision. After introducing modern intelligent algorithm of this paper and the huanggang district regional data integration analysis, algorithm between the groups of mutual competition, won both open and critical criteria. By putting a macro perspective of smallscale comprehensive system construction, obtained the wildcard judging criteria of physical education, not only for huanggang region, the algorithm and implementation of network group of abstract, generalization algorithm model can be in any actual region of physical education evaluation policy.

Huanggang as the education of Hubei province's ace in the hole, it has the very big superiority and facing a rare development opportunity. But under the influence of the overall economic environment, although middle school basketball movement development has made great progress, many school basketball game has a different form, annual, city high school basketball game also held on a regular basis. Many schools have formed the amateur training team, but still in the stage of the school basketball concrete implementation many of the problems, make school class inside and outside of basketball sports healthy development, further enhance the students' lifelong sports consciousness, cultivate the comprehensive development of sports reserve talent is very important, high school basketball as one of the most important standing of the school basketball sports, to play the basketball inheritance, realizes the sustainable development and the role of lifelong physical exercise. School basketball movement development as an important link in school sports, diversity, sites, in the form of its flexibility and extensive participation more and more widely attention, in addition, the basketball movement after hundred years of development, increasingly social value and culture, is the science of integrating multiple disciplines disciplines, the display with a unique and comprehensive education function, the avant-garde "basketball culture" concept is being more and more people understanding and acceptance.

\section{ACKNOWLEDGMENT}

Huanggang normal university in 2015 to support key projects: huanggang (region) of middle school basketball sports present situation and development countermeasure research, project number: (201501920). 


\section{REFERENCE}

[1] Li Xishui, 2007. Theory of CUBA matches reflects the cultural connotation and the construction of campus basketball culture. Journal of changchun normal university: natural science edition, 26 (10): 121-123.

[2] YanCheng spring, xiang-yang CAI, Chen Tiecheng, 2006. Research on campus basketball culture education. Journal of sports science research, $10(2): 100-102$.

[3] shuang-wen wu, 2005. On college students' sports level of the CUBA basketball league and backup talent cultivation research [J]. Journal of wuhan sports college, 35 (4) : 69-71.

[4] Song WenZu, 2013, Study on the analysis and simulation of fosbury flop technique based on the sports biomechanics. Biotechnol. An Indian J., 8(10): 1331-1336.

[5] Chen Chao, Lu Guang, Ebadi Abdol Ghaffar,2013, Mathematical model of nonlinear distortion and linear error correction for soccer robot vision system. Biotechnol. An Indian J., 8(6): 733737.

[6] Liang Tiehuai , 2013, Based on the statistics of the long jump athletes three-dimensional force analysis of jumping. Information Technology Journal, 12(15): 3345-3348. DOI: 10.3923/itj.2013.3345.3348.

[7] Pu Sheng, 2013, Biomechanical analysis of the influencing factors on fitness running leg's stomp effect. Information Technology Journal, 12(19): 5085-5090. DOI: 10.3923/itj.2013.5085.5090.

[8] Xing Jinming, Jiang Yong, Yuan Wenxue, Liu Liqing, 2013, The application of grey comprehensive evaluation model in the sports industry research. International Journal of Applied Mathematics and Statistics, 48(18): 461-468.

[9] Tang Dingyu, Ma Gang, Guo Jun, 2013, Applications of Monte Carlo algorithm in research on the basketball hit rate of ideal hollow shooting based on Matlab Simulation. Information Technology Journal, 12(15): 3315-3319. DOI: 10.3923/itj.2013.3315.3319.

\section{AUTHOR'S BIOGRAPHY}

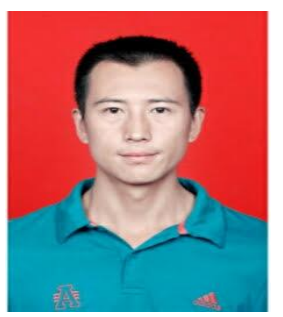

Weiqi Jiang (1983- ) male, Korea, master graduate student, lecturer. Methods: social sports, the sports education. 